Beau Sievers

Harvard University

beau@beausievers.com

Evan DeFilippis

Harvard University

defilippis@g.harvard.edu

\title{
Causal complexity demands community coordination
}

N.B.: This is a commentary on Tal Yarkoni's paper The Generalizability Crisis (available at: https://psyarxiv.com/iqw35), the target article for a forthcoming issue of Behavioral and Brain Sciences.

\begin{abstract}
Yarkoni's argument risks skepticism about the very possibility of social science: If social phenomena are too causally complex, normal scientific methods could not possibly untangle them. We argue that the problem of causal complexity is best approached at the level of scientific communities and institutions, not the modeling practices of individual scientists.
\end{abstract}

\section{Main text}

The argument advanced by Yarkoni (this issue) is, at its core, the problem of provisos, a skeptical dilemma in the philosophy of science posed by Hempel (1988) and Lange (1993): Claims that require ceteris paribus assumptions (i.e., that hold only "all else being equal") either overgeneralize, in which case they are false, or they depend on an unbounded set of provisos, in which case they are vacuous. What distinguishes Yarkoni's account from prior formulations is his simultaneous embrace of both horns of the dilemma: Scientists must fully align their verbal and statistical claims, and either abandon generalization or use very large models that favor prediction over explanation.

Building models large enough to match verbal claims might be quite difficult, and the target article says very little on how to go about it. Disturbingly, we are warned that model growth could be unbounded-we should be prepared to add factors "ad infinitum," with the understanding that "reality is not under any obligation to only manifest sparse causal relationships that researchers find intuitive." Without qualification, this opens the door to two more skeptical challenges: underdetermination and the problem of unconceived alternatives. If the true causal structure of reality is complex and unbounded, then any empirical finding could be caused by more than one independent mechanism, and all scientific theory would be underdetermined by the available evidence (Quine, 1951). Worse, if the nature of causality is inaccessible to human intuition, then even if we cobble together an instrumentally useful theoretical framework, we should expect it to be undermined by alternatives that we could not possibly conceive of (Stanford, 2006). 
Following these skeptical implications, it seems to us that the true antagonist of Yarkoni's story is not the unfortunate tendency of social scientists to make sloppy verbal generalizations, but rather the complex causal structure of reality itself. Better alignment between verbal and statistical claims may make the problems of causal complexity easier to see, but it will not do much to solve them. Where Yarkoni asks why social scientists are so slapdash in their verbal treatment of statistics, we would ask instead: Are the institutions of social science competent to manage the challenges posed by the causal complexity of social phenomena?

One reason for optimism is that social scientists do occasionally come to generalizable conclusions without large statistical models or full alignment of verbal and statistical claims. For example, Knetsch and Sinden (1984) speculated that the endowment effect would generalize broadly, despite using a model that did not permit generalization beyond students at the University of New England trading lottery tickets for $\$ 3$ in the year 1984. Later research iteratively modified this generalization scope, showing that the endowment effect extends across goods (e.g. van Dijk \& van Knippenberg, 1998; Rowe, D'Arge, \& Brookshire, 1980), age groups (Harbaugh, Krause, \& Vesterlund, 2001), cultures (Maddux et al., 2010), and species (Lakshminaryanan et al., 2008), but is limited by market features (Kahneman, Knetsch, \& Thaler, 1990), learning (Hovis, \& Schulze, 1987; Apicella et al., 2014), and expertise (List, 2003). At the risk of overgeneralizing from a single example, this shows that the familiar, messy process of iterative science is in some cases capable of untangling the causal structure of social phenomena. Importantly, this process depends on scientists pragmatically understanding over- or under-generalization as opportunities to contribute. Nuanced research cannot get off the ground if there is nothing to nuance.

But how should scientists identify unmeasured factors? The target article recommends "careful, critical thinking," which is somewhat vague. In practice, this critical thinking does not take place inside the head of a single scientist, but through dialog within a broad community of scholars with diverse backgrounds and areas of expertise. Accordingly, the diversity of the scientific community may be a better target for intervention than statistical modeling practice. Achieving what Harding (1992) calls "strong objectivity" will require creating variation not only in experimental factors, but also in the social standpoints of the people who select those factors, determining the direction of scientific research.

Diversifying the population of researchers is not the only way institutions can mitigate the problem of unconceived alternatives. For example, a bias against the publication of null results disincentivizes research that could limit the generalization of previous findings. Exactly this problem plagued research on social priming, contributing to the replication crisis in psychology. Similar effects may follow from a preference for funding "low-risk" projects by eminent scientists (Stanford, 2019) and the gatekeeping function of prepublication peer review (Heesen \& Bright, 2020). 
One promising approach is to explicitly incentivize revealing unconceived alternatives. Beyond alignment of verbal and statistical claims, authors could be required to anticipate the unmeasured conditions they suspect are necessary and sufficient to realize the observed effects. This would have the upshot of pre-committing researchers to accept certain conceptual replications, even when faced with null results. Building on Yarkoni's advocacy of predictive, translational research, institutions could encourage interdisciplinary collaborations for identifying mechanisms of action and limits to generalization, as well as adversarial collaborations between researchers with competing hypotheses. These efforts could be augmented by the maintenance of prediction markets for aggregating the knowledge and expertise of the broader scientific community (e.g., https://socialscienceprediction.org/).

These recommendations assume that the causal complexity of social phenomena is not so extreme as to bring researchers to skeptical grief. The (admittedly partial) successes of the social sciences seem to support this assumption, while the field's failures seem plausibly caused by perverse incentives and institutional mismanagement. We are enthusiastic about some of Yarkoni's recommendations - in particular, designing for variation is a fantastic idea and we have sought to do so in our own research (Sievers et al., 2019). But insofar as generalization depends on identifying blind spots and missed opportunities, reforms that focus on the statistical practices and thinking habits of individual scientists will likely fall short of the mark. We must also foster a diverse scholarly community that is incentivized to reveal what those who came before them have missed.

\section{Conflicts of interest: None.}

Funding: This research received no specific grant from any funding agency, commercial or not-for-profit sectors.

\section{References}

Apicella, C. L., Azevedo, E. M., Christakis, N. A., \& Fowler, J. H. (2014). Evolutionary Origins of the Endowment Effect: Evidence from Hunter-Gatherers. American Economic Review, 104(6), 1793-1805. https://doi.org/10.1257/aer.104.6.1793

Coursey, D. L., Hovis, J. L., \& Schulze, W. D. (1987). The Disparity Between Willingness to Accept and Willingness to Pay Measures of Value. The Quarterly Journal of Economics, 102(3), 679-690. https://doi.org/10.2307/1884223

Harbaugh, W. T., Krause, K., \& Vesterlund, L. (2001). Are adults better behaved than children? Age, experience, and the endowment effect. Economics Letters, 70(2), 175181. https://doi.org/10.1016/S0165-1765(00)00359-1

Harding, S. (1992). Rethinking standpoint epistemology: What is "strong objectivity?" The Centennial Review, 36(3), 437-470. 
Heesen, R., \& Bright, L. K. (2020). Is peer review a good idea? The British Journal for the Philosophy of Science. https://doi.org/10.1093/bips/axz029

Hempel, C. G. (1988). Provisos: A Problem Concerning the Inferential Function of Scientific Laws, in A. Grünbaum and W. Salmon (eds.) The Limits of Deductivism, University of California Press, Berkeley, CA.

Kahneman, D., Knetsch, J. L., \& Thaler, R. H. (1990). Experimental Tests of the Endowment Effect and the Coase Theorem. Journal of Political Economy, 98(6), 13251348. https://doi.org/10.1086/261737

Lakshminaryanan, V., Keith Chen, M., \& Santos, L. R. (2008). Endowment effect in capuchin monkeys. Philosophical Transactions of the Royal Society B: Biological Sciences, 363(1511), 3837-3844. https://doi.org/10.1098/rstb.2008.0149

Lange, M. (1993). Natural Laws and the Problem of Provisos, Erkenntnis 38, 233-248.

List, J. A. (2003). Does Market Experience Eliminate Market Anomalies?*. The Quarterly Journal of Economics, 118(1), 41-71. https://doi.org/10.1162/00335530360535144

Maddux, W. W., Yang, H., Falk, C., Adam, H., Adair, W., Endo, Y., Carmon, Z., \& Heine, S. J. (2010). For Whom Is Parting With Possessions More Painful?: Cultural Differences in the Endowment Effect. Psychological Science, 21(12), 1910-1917.

https://doi.org/10.1177/0956797610388818

Rowe, R. D., D'Arge, R. C., \& Brookshire, D. S. (1980). An experiment on the economic value of visibility. Journal of Environmental Economics and Management, 7(1), 1-19. https://doi.org/10.1016/0095-0696(80)90018-2

Quine, W. V. O. (1951). Two Dogmas of Empiricism. The Philosophical Review, 60(1), 20-43.

Sievers, B., Lee, C., Haslett, W., \& Wheatley, T. (2019). A multi-sensory code for emotional arousal. Proceedings of the Royal Society B, 286(1906).

Stanford, P. K. (2006). Exceeding our grasp: Science, history, and the problem of unconceived alternatives. Oxford University Press, Oxford, UK.

Stanford, P. K. (2019). Unconceived alternatives and conservatism in science: the impact of professionalization, peer-review, and Big Science. Synthese, 196(10), 39153932.

van Dijk, E., \& van Knippenberg, D. (1998). Trading wine: On the endowment effect, loss aversion, and the comparability of consumer goods. Journal of Economic Psychology, 19(4), 485-495. https://doi.org/10.1016/S0167-4870(98)00020-8 